\title{
Phenotype-Guided Asthma Therapy: An Alternative Approach to Guidelines
}

This article was published in the following Dove Press journal:

Journal of Asthma and Allergy

\section{Luis Pérez de Llano (DD \\ David Dacal Rivas \\ Nagore Blanco Cid \\ Irene Martin Robles}

Head of the Pneumology Service, Lucus Augusti University Hospital, EOXI Lugo, Monforte, Cervo. C/ Doctor Ulises

Romero, $n^{\circ}$ I, Lugo, 27003, Spain
Correspondence: Luis Pérez de Llano Head of the Pneumology Service, Lucus Augusti University Hospital, EOXI Lugo, Monforte, Cervo, C/Doctor Ulises

Romero, $n^{\circ}$ I, Lugo, 27003, Spain

Tel +34982296000

Email eremos26@hotmail.com

\begin{abstract}
Despite recent advances in therapy, a substantial proportion of asthmatics remain not well controlled. The classical stepwise approach to pharmacological therapy in adult asthma recommends that treatment is progressively stepped up by increasing the inhaled corticosteroid (ICS) dose or by adding another controller medication- to achieve symptom control and reduce the risk of exacerbations, and stepped down after a period of control. In general, asthma guideline recommendations do not reflect that there are significant differences between ICS in terms of potency. Moreover, they do not consider efficacy and safety separately, incorrectly assuming that "low" and "high" dose categories inevitably correspond with low and high risk of systemic effects. Another point of criticism is the fact that guidelines do not take into account the inflammatory profile of the patient, although substantial groups of patients with mild and moderate asthma have little evidence of "T2high" inflammation, and by extension are likely to show a poor response to ICS treatment. On the other hand, the latest version of the Global Initiative for Asthma (GINA) equally recommends regular ICS and ICS/formoterol as needed to prevent exacerbations in step 2 patients, without taking into consideration that the therapeutic objectives (exacerbations, symptoms) may differ between individual patients and that different goals may warrant distinct treatment strategies. In this review, we bring to the table several controversial issues concerning asthma treatment and suggest an alternative proposal that takes into consideration the potential side effects of high ICS doses, the patient's inflammatory profile and the therapeutic goals to be achieved.
\end{abstract}

Keywords: asthma, asthma treatment, asthma phenotype, asthma endotype, personalized medicine

\section{The Current Status of Asthma}

Asthma is defined by the Global Initiative for Asthma (GINA) as

a heterogeneous disease, usually characterized by chronic airway inflammation. It is characterized by the history of respiratory symptoms such as wheeze, shortness of breath, chest tightness and cough that vary over time and in intensity, together with variable expiratory airflow limitation. ${ }^{1}$

Asthma is one of the most common chronic respiratory disease worldwide and more than 339 million people suffer from this disease. ${ }^{2}$ Overall, asthma mortality has reduced markedly from 0.44 deaths per 100,000 people in 1993 to 0.19 in $2006,{ }^{3}$ due in part to improved diagnosis, but also due to better treatment, particularly with the widespread use of inhaled corticosteroids (ICS). However, there was no appreciable change in global asthma mortality rates from 2006 through to 2012 , 
when the estimated rate was also 0.19 deaths per 100000 people $(0.16-0.21){ }^{3}$ It has been shown that about $50 \%$ of asthma deaths might be preventable if guidelines' recommendations are followed. ${ }^{4}$

On the other hand, a study conducted among 8000 patients with asthma from 11 European countries showed that $45 \%$ of them had uncontrolled asthma, $44 \%$ used oral corticosteroids in the previous 12 months, $24 \%$ visited an emergency department and $12 \%$ were hospitalized. ${ }^{5}$ These figures are very similar to those reported in the National Health and Wellness Survey: 54\% of patients had asthma that was not well controlled. ${ }^{6}$ This means that, even in European developed countries, a substantial proportion of asthmatics remain not well controlled, resulting in a significant impact on health resources and patients' health status. While the reasons underlying poor asthma control are multifactorial and include medication access and compliance, to achieve further reduction in asthma mortality novel strategies will also be required.

\section{Heterogeneity of Asthma: Phenotypes, Endotypes and Biomarkers}

One of the reasons that could explain this unsatisfactory situation is the limited importance that guidelines place on asthma heterogeneity. ${ }^{1}$ Asthma treatment guidelines have proven useful in standardizing care approaches and improving outcomes but, although evidence continues to build regarding the existence of different cell types, inflammatory pathways, environmental exposures, and other factors that produce a similar set of symptoms known collectively as asthma, the movement from a "one size fits all" symptom-based strategy to a more patientcentered, individualized approach to treatment, has not resulted in official and widely accepted recommendations.

The first attempt to disentangle asthma heterogeneity was the identification of different phenotypes in the past two decades. In this context, "phenotype" is defined as observable characteristics (clinical, demographic or physiological features, trigger-related or general inflammatory processes) that may or may not be associated with underlying disease mechanisms. Unbiased clustering algorithms that have the capacity to incorporate a range of "observable" variables have been applied to large patient datasets (SARP: Severe Asthma Research Program, ADEPT: Airway Disease Endotyping for Personalized Treatment, U-BIOPRED: Unbiased BIOmarkers in PREDiction of
Table I Asthma Phenotypes

\begin{tabular}{|l|l|}
\hline Major asthma phenotypes & $\begin{array}{l}\text { Early-onset allergic asthma } \\
\text { Late-onset eosinophilic asthma } \\
\text { Late-onset non-eosinophilic asthma }\end{array}$ \\
\hline $\begin{array}{l}\text { Symptom-based } \\
\text { phenotypes }\end{array}$ & $\begin{array}{l}\text { Exacerbation prone } \\
\text { Cough variant } \\
\text { Obesity-related asthma } \\
\text { Asthma with persistent airflow } \\
\text { obstruction }\end{array}$ \\
\hline $\begin{array}{l}\text { Trigger-induced } \\
\text { phenotypes }\end{array}$ & $\begin{array}{l}\text { Exercise induced } \\
\text { Occupational asthma } \\
\text { Seasonal asthma } \\
\text { Aspirin exacerbated respiratory disease }\end{array}$ \\
\hline Biomarker-based & $\begin{array}{l}\text { Eosinophilic asthma } \\
\text { Neutrophilic asthma } \\
\text { Paucigranulocytic asthma } \\
\text { Mixed granulocytic asthma }\end{array}$ \\
\hline Treatment-based & Steroid-resistant asthma \\
\hline
\end{tabular}

respiratory disease outcomes) to objectively characterize clinical phenotypes of asthma. ${ }^{7-12}$ These efforts resulted in the identification of several phenotypes, listed in Table 1. However, it remains unclear how well these phenotypes reflect specific biologic pathways because there is heterogeneity within every phenotype cluster, the clusters significantly overlap, they can vary over time and the methodology used and cohorts examined diverge widely. The great majority of these studies have been conducted in severe asthmatics, those who impose more undue burden for clinicians and health care providers.

Quite soon, it became clear that an understanding of the underlying mechanisms of asthma cannot be achieved from just an analysis of symptoms and signs and of physiologic or even inflammatory markers. The term "endotype" refers to a subtype of a complex condition with well-defined pathophysiologic mechanisms that are specific and distinct from other endotypes. ${ }^{13}$ Thus, this concept is highly demanding and, honestly, it should be acknowledged that no "true" endotypes have been as yet described with certainty, and endotyping remains an ongoing work, which is too early to translate into clinical care. It is of note that similar symptoms and observable features can arise through different pathophysiological mechanisms and that consequently different endotypes may have similar, or even the same phenotype. Moreover, similar molecular mechanisms may be present in different asthma phenotypes. Identifying true 
endotypes of asthma and their underlying mechanisms is a prerequisite for achieving better mechanism-based treatment targeting, and ultimately delivery of genuinely stratified medicine in asthma. Although incompletely defined, two major endotypes have been distinguished: "T2-high" (defined by increased type 2 cytokine release or epithelial gene expression compared to a reference population) and "T2-low" asthma (usually identified by excluding a T2-high profile). ${ }^{14}$

Biomarkers represent, among other things, measurable indicators linking an underlying pathway to a phenotype of a disease. The most employed ones in the routine clinical practice of asthma are: blood eosinophils, induced sputum cell count, fraction of exhaled nitric oxide (FeNO) and IgE. Although only $50 \%$ of asthma patients are identified with T2 airway inflammation, ${ }^{15}$ there is a paucity of biomarkers for T2-low asthma (almost only induced sputum cell count). Table 2 reflects the advantages and disadvantages of each biomarker.

Even though blood or sputum eosinophils are the most commonly used biomarkers to recognize $\mathrm{T} 2$ inflammatory response, are far from optimal in this respect. When asthma

Table 2 T2-High Biomarkers. Advantages and Disadvantages

\begin{tabular}{|c|c|c|}
\hline Biomarker & Advantages & Disadvantages \\
\hline Blood Eos & $\begin{array}{l}\text {-Widely available. } \\
\text {-Predicts response to } \\
\text { mAbs. }\end{array}$ & $\begin{array}{l}\text {-Treatment affects the } \\
\text { values. } \\
\text {-Discordance with sputum } \\
\text { Eos. } \\
\text {-Varies over time. }\end{array}$ \\
\hline $\begin{array}{l}\text { Sputum cell } \\
\text { Count }\end{array}$ & $\begin{array}{l}\text {-Gold standard. } \\
\text {-Predicts response to } \\
\text { mAbs. }\end{array}$ & $\begin{array}{l}\text {-Limited use. } \\
\text {-Technically demanding. } \\
\text {-Treatment affects the } \\
\text { values. } \\
\text {-Varies over time. }\end{array}$ \\
\hline $\mathrm{FeNO}$ & $\begin{array}{l}\text {-Widely available. } \\
\text {-Predicts response to } \\
\text { dupilumab. }\end{array}$ & $\begin{array}{l}\text {-Multiple confounders. } \\
\text {-Treatment affects the } \\
\text { values. } \\
\text {-Discordance with sputum } \\
\text { Eos. } \\
\text {-Varies over time. }\end{array}$ \\
\hline $\lg \mathrm{E}$ & $\begin{array}{l}\text {-Widely available. } \\
\text {-Specific IgE helps } \\
\text { allergy diagnosis. } \\
\text {-Predicts response to } \\
\text { omalizumab. }\end{array}$ & $\begin{array}{l}\text {-Total IgE is a poor } \\
\text { biomarker of T2-asthma. }\end{array}$ \\
\hline
\end{tabular}

Abbreviations: Eos, eosinophils; FeNO, fraction of exhaled nitric oxide; IgE, Immunoglobulin E; T2, type 2 asthma. patients are classified according to the expression of IL-13 inducible genes, sputum eosinophils show an area under the ROC (receiver operating characteristic) curve of 0.78 to identify a "T2-high" profile. This figure is 0.68 for blood eosinophils, 0.67 for FeNO, 0.62 for $\operatorname{IgE}$ and 0.55 for periostin. ${ }^{16}$ Therefore, it remains to be established the most appropriate gold standard for identifying this endotype.

\section{Therapeutic Goals and Treatable Traits}

Some influential authors have already proposed leaving behind the approach based on phenotypes or endotypes in order to adopt a pragmatic view through the identification of "treatable traits" (TT) for each particular patient. $^{17-19}$ Although more evidence to support this approach is needed, McDonald et al found that severe asthma management targeted to predefined TT leads to significant improvements in health-related quality of life, asthma control and reduced primary care acute visits. ${ }^{20}$

Another proposal is to separate what we want to improve in each patient, the therapeutic goals (TG) from the characteristics (TT) upon which action may be taken in order to achieve this improvement. ${ }^{21} \mathrm{TG}$ are, ultimately, the clinical needs of patients (symptoms, exacerbations, quality of life, physical activity) or aspects of the disease (progression, mortality) that should be avoided in order to improve prognosis. They are not truly therapeutic targets, but rather clinical problems that must be eliminated or improved. Most patients have several $\mathrm{TG}$ and it is possible to achieve different TG with a single therapeutic intervention. On the other hand, TT are the clinical, physiological, or biological characteristics present in each individual patient, and they must be identifiable and quantifiable through biomarkers or specific diagnostic tests. They must, themselves, have an impact on one of the TG (that is, there must be a clear relationship between the value the TT takes and that of the TG in question; eg: more eosinophils, more exacerbations). Treatment, through the improvement of the value of the TT must, as a result, improve one or more TG. Table 3 lists the TG and TT in asthma. Figure 1 exemplifies a typical clinical case.

Two types of TG can be contemplated: symptoms and quality of life improvement, and reduction of the risks involved in the disease and its treatment. The central TG is the reduction of mortality, something that has nearly 
Table 3 Therapeutic Goals and Treatable Traits in Asthma

\begin{tabular}{|l|l|l|}
\hline Therapeutic Goals & Treatable Traits & Biomarker Associated to Therapeutic Trait \\
\hline Reduction of symptoms: & -Bronchial obstruction & -FEVI \\
-Dyspnoea & -Non-adherence & -Questionnaires \\
-Night awakenings & -Aggravating factors (allergens, & -Environmental levels \\
-Health-related quality of life & environmental pollution, etc.) & \\
Reduction of risk: & -Allergy & -Specific IgE, skin prick tests \\
-Reduce mortality & -Smoking & -CO-oximetry \\
-Reduce progression of the disease & -Comorbidities & -Variable in each case \\
-Prevent exacerbations & -Eosinophilia & -Eosinophils in blood or airways \\
-Reduce adverse effects of medication & - Chronic infection & -Germ isolation \\
\hline
\end{tabular}

been achieved in asthma after the widespread use of ICS; ${ }^{22}$ nonetheless, deaths are still recorded, even in developed countries, but they are usually associated with poor social conditions. $^{23}$

Exacerbations impact heavily on the quality of life of asthmatics, $^{24}$ as they are risk factors for mortality ${ }^{25}$ and also for loss of lung function. ${ }^{26}$ Besides, it is essential to avoid the iatrogeny associated to the treatment, which is especially relevant in the case of systemic corticosteroids. $^{27}$ Control of symptoms is an unquestionable TG in asthma, taking into account its relationship to the quality of life of patients. Moreover, poor symptomatic control entails a greater risk of exacerbations. ${ }^{28}$

TT in asthma include the following:

*Therapeutic non-adherence (TNA). It is well established that TNA in asthma is a risk factor for exacerbations. ${ }^{29}$ Several reminder systems (e-mails, telephone ...) have demonstrated to improve adherence $^{30}$ and it seems reasonable to detect and reduce TNA, although some doubts still persist concerning their impact on asthma control. ${ }^{31}$

*Tobacco use. Smoking worsens asthma control in a dose-dependent way ${ }^{32}$ and it can change the profile of the underlying inflammatory response, making it steroidresistant. ${ }^{33}$ However, quitting the habit improves both the lung function and symptoms of asthmatics. ${ }^{34}$

*Comorbidities. Comorbid conditions (rhinitis, sinusitis, nasal polyps, allergic bronchopulmonary aspergillosis, gastro-oesophageal reflux, psychiatric disorders, obesity, inducible laryngeal obstruction, bronchiectasis and obstructive sleep apnoea) may share with asthma metabolic and inflammatory pathways, they can have a causal connection, or in some instances, both. Comorbidities increase the likelihood of poorly controlled asthma ${ }^{35}$ and specific treatment for any of them can improve it, as occurs for instance with nasal polyposis and obstructive apnoea syndrome during sleep. ${ }^{36,37}$

\section{Medical history.}

-45 year old.

-Asthma onset at 35.

-Negative skin prick test.

-Blood eosinophils: 500 cells $/ \mathrm{mm}^{3}$.

-Treatment: budesonide $320 \mu \mathrm{g} /$ formoterol

$9 \mu \mathrm{g}$ t.d.

-Two severe exacerbations in the prior 12 months.

-Asthma control test: 14.

-FEV1: $72 \%$ predicted.
Therapeutic goals. -Exacerbations. -Symptoms.

Biomarkers. -Blood eosinophils. -FEV1.

Treatable traits. -Bronchial obstruction -Eosinophilia.

Figure I A clinical example of therapeutic goals and treatable traits. 
*Bronchial obstruction. In asthma, FEV1 below $80 \%$ of the theoretical value is an independent predictor of exacerbations ${ }^{38}$ and poor lung function is related (albeit imperfectly) to symptoms of the disease. ${ }^{39}$ Further, several clinical trials have demonstrated the addition of tiotropium to a combination of ICS and long-acting $\beta-2$ agonists (LABA) in poorly controlled asthmatics with bronchial obstruction achieves significant functional improvement (approximately $100 \mathrm{~mL}$ ) and exacerbations reduction of $21 \%,{ }^{40}$ accompanied by symptomatic improvement independently of the blood eosinophil number. ${ }^{41}$

*T2 Inflammation. The presence of T2 inflammation, measured by the analysis of blood or sputum eosinophils, is associated with poorer asthma control and more exacerbations. ${ }^{42}$ Besides, it has been proven that eosinophilia is a good predictor of corticosteroid response ${ }^{43}$ and that adjusting the treatment of severe asthma on the basis of sputum eosinophilia reduces exacerbations. ${ }^{44}$ The role of anti-interleukin-5 (anti-IL-5) and anti-IL-4 and 13 monoclonal antibodies in the treatment of severe eosinophilic asthma has been clearly established. ${ }^{45}$

*Chronic bronchial infection. The isolation of Pseudomonas Aeruginosa has been shown to be associated to greater risk of exacerbation, and the AMAZES study demonstrated that azithromycin at a dose of $500 \mathrm{mg} 3$ times a week, as an add-on to the usual medication, is effective in reducing severe exacerbations and improving the quality of life of asthmatics with suboptimal control despite a combination of ICS/ LABA,${ }^{46}$ although it remains to be fully elucidated to what extent macrolides' efficacy in asthma is due to their antiinflammatory or antibacterial effects (or both).

*Allergy. Immunotherapy reduces asthma symptoms and use of asthma medications and improves bronchial hyperreactivity, ${ }^{47}$ whereas evidence supporting the efficacy of allergen avoidance is still weak and subject of controversy. ${ }^{48}$

*Exhaled nitric oxide fraction (FeNO). Despite the fact that it is widely used in the routine clinical practice, there is ongoing controversy as to whether adjusting treatment on the basis of its values improves asthma control, and neither is there a well-established cut-off point separating what is normal from pathological. Consequently, a recent review in the Cochrane database advises against this practice (except, maybe, in patients with frequent exacerbations). ${ }^{49}$

*Bronchial hyperresponsiveness (BHR). Asthma control and degree of BHR do not show a close relationship, and a large percentage of patients with good control of the disease exhibit ongoing BHR. The AMPUL study ${ }^{50}$ demonstrated that adjusting medication on the basis of methacholine test resulted in lung function improvement and exacerbations (mild ones) reduction, but a single study does not seem to provide enough evidence to consider BHR a TT.

\section{Guidelines' Recommendations}

The classical stepwise approach to pharmacological treatment in adult asthma recommends that asthma treatment is progressively stepped up (by increasing the ICS dose or by adding another controller medication) to achieve symptom control and reduce the risk of exacerbations, and stepped down after a period of control. ${ }^{1}$

The guidelines also provide a table that classifies the different doses for each IC into low, medium and high doses, and this is very pertinent, since high doses are associated with undesirable side-effects. It is important to note that it is not a table of equivalence since ICS has different pharmaceutical properties in terms of potency and therapeutic index. We shall deal with this matter in detail later.

The chief novelty of the latest edition of the GINA guidelines is that treating asthma patients with short-acting $\beta 2$-agonists (SABA) alone is no longer advocated. Instead, they should receive symptom-driven ICS/formoterol. It has been reported that $30-37 \%$ of adults with acute asthma and $16 \%$ of patients with near-fatal have mild forms of the disease. ${ }^{51}$ On the other hand, dispensing of $\geq 3$ canisters per year (average 1.7 puffs/day) is associated with higher risk of emergency department presentations. ${ }^{52}$ In consequence, GINA equally recommends regular ICS and ICS/formoterol as needed to prevent exacerbations in step 2 patients. ${ }^{1}$ This recommendation is based on the results of 4 clinical trials (two randomized placebo-controlled studies collectively known as SYGMA project and two real-life studies: Novel START, and the PRACTICAL trial) that explored the potential benefits of substituting SABA with budesonide/formoterol as rescue medication in patients with mild asthma. ${ }^{53-56}$ Additionally, asneeded therapy with ICS/formoterol is preferred over SABA for all asthmatics, irrespective of the disease severity.

\section{Limits of the Guidelines: Gaps to Be Filled \\ Mild Asthma}

Results from SYGMA studies led to the conclusion that, in GINA step 2 patients, the fixed combination of budesonide/ formoterol on-demand provided better asthma control than SABA as needed during a 52-week period, although asthma control was poorer than with budesonide maintenance therapy ${ }^{53,54}$ Regarding the prevention of exacerbations, budesonide/formoterol on-demand showed the same benefits as 
chronic ICS treatment in this population of mild asthma patients. Two real-life trials have been published later: the Novel START study, which yielded similar results than those of the SYGMA project, ${ }^{55}$ and the PRACTICAL study (which recruited patients with mild and moderate asthma), that showed a modest benefit (in terms of severe exacerbations prevention) of budesonide/formoterol as needed compared to maintenance ICS and SABA as needed. ${ }^{56}$ On balance, it seems that as needed budesonide/formoterol is, at least, as effective as maintenance ICS in preventing exacerbations and, on the contrary, it seems that regular ICS is superior than budesonide/ formoterol on-demand to control symptoms.

However, as stated above, in the routine clinical practice we need to identify the specific TG (one or more) we want to achieve in an individual patient in order to prescribe the most adequate therapeutic option. We can face several clinical problems, but mainly a combination of symptoms and exacerbations. If the TG is improving symptoms, if the patient is free of exacerbations, why should we use budesonide/formoterol asneeded as the preferred option instead of regular ICS? We could argue that we must consider the expected risk of nonadherence, but in our opinion, the best choice might be to offer the patient the possibility of being compliant with regular ICS and to use ICS/formoterol as a reliever, ${ }^{1}$ although we have to acknowledge that this approach needs to be demonstrated in a clinical trial. Figure 2 schematizes this personal approach to mild asthma treatment.

\section{Moderate to Severe Asthma}

As above-mentioned, the classical approach to pharmacological treatment in adult asthma is based on a progressive step-up of therapy, and this can lead to overtreatment, a concern that has been raised by a number of opinion leaders. ${ }^{57}$ In fact, guidelines do not take into account the dose-response relationship of ICS in adult asthma, despite it has been demonstrated that, in randomized placebo-controlled trials of fluticasone propionate (FP) in adults with asthma, $80 \%$ of the benefit obtained at $1000 \mu \mathrm{g} / \mathrm{d}$ was achieved at doses of 70-180 $\mu \mathrm{g} / \mathrm{d}$ and $90 \%$ at a dose of $100-250 \mu \mathrm{g} / \mathrm{d}$. The maximum possible effect was obtained with FP doses of around $600 \mu \mathrm{g} / \mathrm{d}^{58}$ Besides, $80-90 \%$ of the maximum therapeutic benefit of budesonide was achieved with a dose between 200 and 600 $\mu \mathrm{g} / \mathrm{d}$, and the maximum effect was obtained with budesonide doses between 900 and $1100 \mu \mathrm{g} / \mathrm{d} .{ }^{59}$ It could be countered that the dose-response relationship of ICS on airway inflammation is different but clinically important. Nonetheless, bronchial biopsy studies show suppression of airway inflammation that is optimal at a dose of FP $500 \mu \mathrm{g} / \mathrm{d}^{60}$ Taken together, these

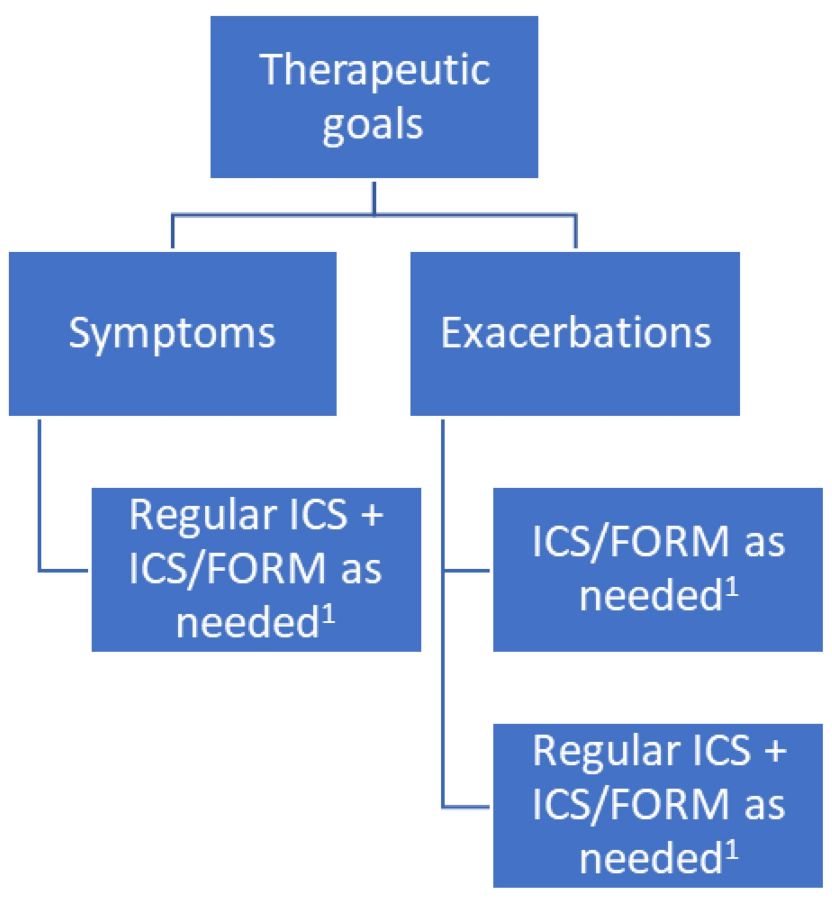

Figure 2 Suggested approach to mild asthma treatment.

Abbreviations: FORM, formoterol; ICS, inhaled corticosteroid; I, reference I.

findings suggest that the ICS dose that achieves at least $80-90 \%$ of the maximum achievable clinical benefit is traditionally classified as a "low dose".

GINA incorporates the traditional terminology of "low", "medium" and "high" doses of ICS $^{1}$ for each specific drug (Table 4). Nonetheless, as acknowledged, this is not a table of equivalence and it is based on available studies and product information, since data on comparative potency are not readily available. In any case, clinicians tend to assume that "high" doses are those marketed presentations containing the highest dose of the ICS. For instance, budesonide/formoterol is commercialized with three doses of budesonide (80, 160 and $320 \mu \mathrm{g}$ ) and a twice-daily dosing of $320 \mu \mathrm{g}$ will be usually considered as "high" by most of the doctors, but "medium" by the guidelines. The effective dose also depends on the inhalation device, the particle size and inhalation maneuver.

In general, asthma guidelines recommend to administer progressively increasing doses of ICS to achieve therapeutic equivalence without reflecting that there are significant differences between ICS in terms of potency. Moreover, they do not consider efficacy and safety separately, incorrectly assuming that "low" and "high" dose categories inevitably correspond with low and high risk of systemic effects. In contrast, a pharmacological study concluded that ICS molecules are not therapeutically similar: across the approved doses for asthma, fluticasone furoate (FF) 
Table 4 Low, Medium and High Daily Doses of Inhaled Corticosteroids

\begin{tabular}{|l|c|c|c|}
\hline Inhaled Corticosteroid & Low Dose & Medium Dose & High Dose \\
\hline Beclometasone dipropionate (PMDI, standard particle, HFA) & $200-500$ & $>500-1000$ & $>1000$ \\
\hline Beclometasone dipropionate (pMDI, extrafine particle, HFA) & $100-200$ & $>200-400$ & $>400$ \\
\hline Budesonide (DPI) & $200-400$ & $>400-800$ & $>800$ \\
\hline Ciclesonide (PMDI, extrafine particle, HFA) & $80-160$ & $>160-320$ & $>320$ \\
\hline Fluticasone furoate (DPI) & $100-250$ & $>250-500$ & $>500$ \\
\hline Fluticasone propionate (PMDI, standard particle, HFA) & \multicolumn{2}{|c|}{200} & \multicolumn{2}{|c|}{400} \\
\hline Mometasone furoate (DPI) & $200-400$ & $>400$ \\
\hline Mometasone furoate (PMDI, standard particle, HFA) & & \\
\hline
\end{tabular}

Abbreviations: DPI, dry powder inhaler; HFA, hydrofluoroalkane propellant; pMDI, pressurized metered dose inhaler.

gave more protection against airway hyperresponsiveness with less systemic activity (measured via 24 -hour plasma cortisol suppression), and had a wider therapeutic index (systemic activity/airway potency ratio), than FP or budesonide. $^{61}$

On the other hand, when we look at GINA steps 3 to 5 , we can see that ICS/formoterol is preferred over SABA as rescue medication. However, this might be a problem in patients who are receiving other combinations such as $\mathrm{FF} /$ vilanterol because we don't have any experience in using two different combinations simultaneously in the same patient. An ICS/SABA combination could be a good alternative for these patients but, although it has been proved effective, ${ }^{62}$ for whatever reason, its use has not been universally adopted.

Another point of criticism is the fact that guidelines do not take into account the inflammatory profile of the patient. McGrath and colleagues demonstrated that $47 \%$ mild to moderate ICS-naive asthmatics had no evidence of sputum eosinophilia in serial samples taken at various points over a 1-year period. Moreover, these "noneosinophilic patients" had no improvement in lung function with ICS but showed evidence of a bronchodilator response consistent with asthma. ${ }^{63}$ These results were corroborated later by Lazarus et al, who found a total of $73 \%$ patients with $<2 \%$ eosinophils in induced sputum cell count in a sample of 295 mild asthmatics. ${ }^{64}$ Taken together, these data would suggest that substantial groups of patients with mild and moderate asthma have little evidence of "T2-high" inflammation, and by extension are likely to show a poor response to ICS treatment.

\section{Towards a New Approach in Asthma Treatment}

Therefore, an alternative approach to the guidelines should contemplate several important aspects:

-High doses of FP ( $\geq 500 \mu \mathrm{g} / \mathrm{d}$ ) or equivalent can lead to side-effects. ${ }^{55}$ In fact, a significant adrenal suppression was found with repeated administration of FP at doses as low as $250 \mu \mathrm{g}$ twice daily. ${ }^{65}$ Guidelines do not consider switching between ICS/LABA formulations and, as mentioned above, there are significant pharmacological differences among ICS (in terms of potency, systemic activity, therapeutic index).

-Asthmatics with "T2-low" profile do not respond to ICS. ${ }^{14}$ High ICS doses should not be prescribed in patients with $\mathrm{T} 2$ low asthma. Instead, these patients can be treated with triple therapy if bronchial obstruction persists, azithromycin to prevent exacerbations ${ }^{46}$ or bronchial thermoplasty in individuals with persistent bronchial hyperresponsiveness. ${ }^{66}$

In this alternative proposal, we suggest to personalize the treatment for asthmatics who remain uncontrolled with FP $500 \mu \mathrm{g} / \mathrm{d}^{67}$ or equivalent. Patients might be classified according to the inflammatory profile identified by biomarkers (blood and sputum eosinophils and FeNO). Taking into account the potency and safety of the ICS that is currently being used, the characteristics of the inhaler device and patients' preferences, a switch to another combination is recommended where applicable. If the patient remains uncontrolled and bronchial obstruction persists despite LABA therapy, a long-acting anticholinergic (LAMA) should be added, since tiotropium has demonstrated to reduce exacerbations and improve symptoms when employed as add-on treatment to ICS/LABA combination, irrespective of the presence/absence of eosinophilia. ${ }^{40,41}$ Recently, several randomized clinical trials have been 
published, showing that different ICS/LABA/LAMA combinations can improve lung function and symptoms in patients with moderate or severe asthma who remain uncontrolled with ICS/LABA. ${ }^{68-70}$

High ICS doses would be only prescribed in "T2-high" patients who have failed prior therapeutic attempts. Consequently, biologic therapy would be restricted to those asthmatics who remain uncontrolled with high-dose ICS triple therapy if they express biomarkers indicative of "T2-high" inflammatory response. In this context, omalizumab has been shown to prevent severe exacerbations, to reduce symptoms and to moderately improve pulmonary function in patients with allergic asthma, irrespective of the blood eosinophil count and FeNO values. Mepolizumab and benralizumab have demonstrated to reduce the need for systemic corticosteroids, to decrease severe exacerbations and to improve asthma control and pulmonary function in patients with $>150$ eosinophils/mm3, regardless of the atopic status. Reslizumab has been proven to reduce severe exacerbations, to diminish symptoms and to improve pulmonary function in adult asthmatics with $>400$ eosinophils $/ \mathrm{mm} 3$, irrespective of whether or not they are atopic. Dupilumab has shown to reduce the need for systemic corticosteroids, to prevent severe exacerbations and to improve asthma control and pulmonary function in atopic

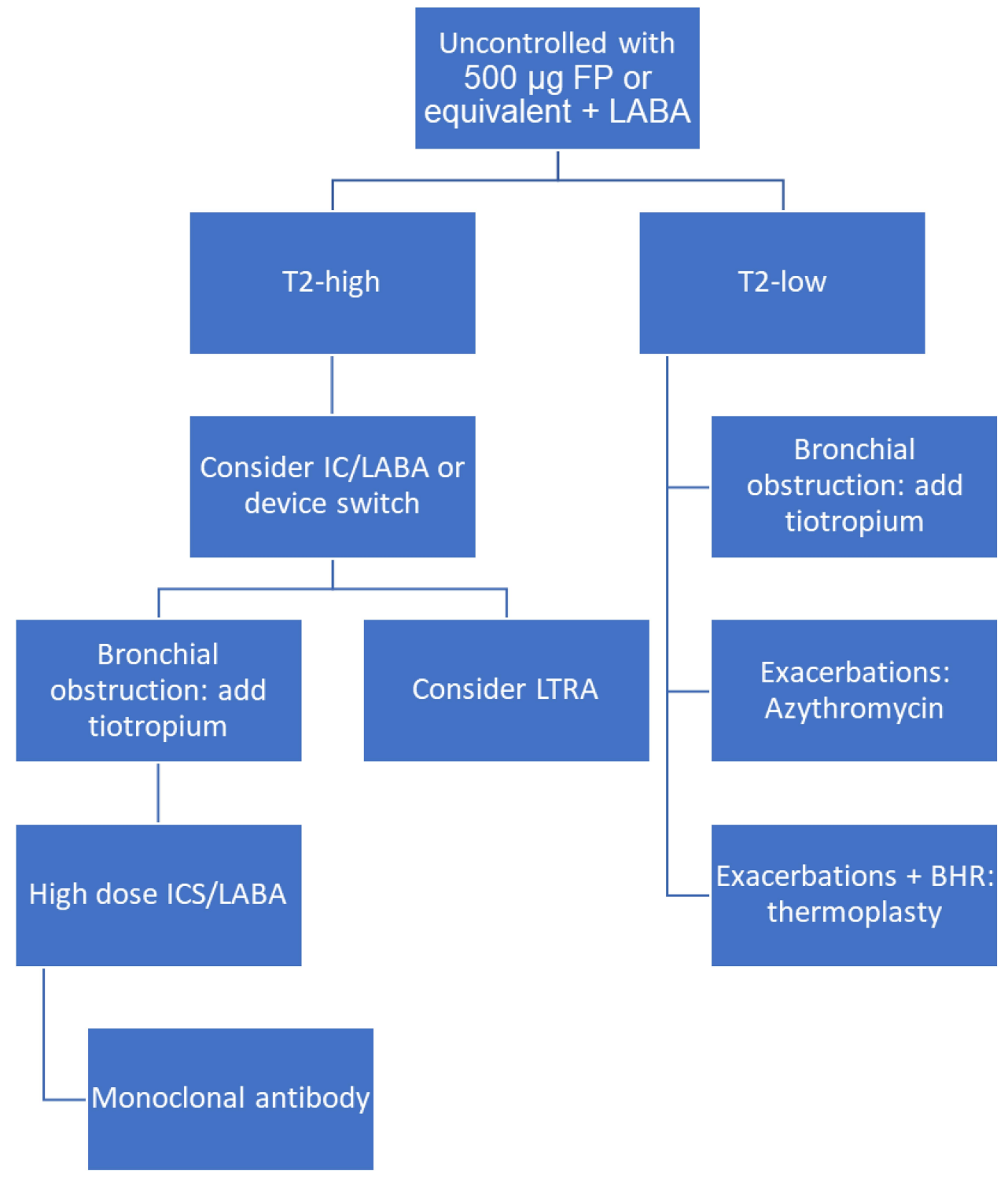

Figure 3 Suggested approach to moderate to severe asthma treatment.

Notes: Reproduced with permission from Pérez de Llano LA, Quirce Gancedo S, Plaza Moral V. Treatment of Moderate-severe Asthma: An Alternative Strategy to the Guidelines Recommendations. Arch Bronconeumol. 2020; S0300-2896(20):30136-30138. ${ }^{67}$

Abbreviations: FP, fluticasone propionate; ICS, inhaled corticosteroid; LABA, long-acting $\beta 2$-agonist; T2, type 2 bronchial inflammation; LTRA, leukotriene receptor antagonist; BHR, bronchial hyperresponsiveness. 
and non-atopic patients with $>150$ eosinophils/mm3 or FeNO $\geq 20$ ppb. $^{71}$ This strategy is schematized in Figure 3 .

The main limitation of this proposal is given by the imperfect biomarkers' balance of sensitivity and specificity ${ }^{16}$ and the difficulty in establishing a cut-off point for each of them, amongst other reasons due to the impact of therapy on blood and sputum eosinophils and FeNO levels. According to the available evidence, a cut-off level of FeNO of 20-30 ppb might be appropriate ${ }^{72}$ and values $>270$ eosinophils/mm3 in blood have a high specificity to identify sputum eosinophilia. ${ }^{73}$ Of note, a subgroup of patients with high FeNO levels ( $>25 \mathrm{ppb}$ ) and low blood eosinophils $(<2 \%)$ has been recently described. ${ }^{74,75}$ As biomarkers are more likely to reflect the inflammatory pattern of a given patient, the dream of a personalized medicine will come true, perhaps through the routine use of -omics in clinical practice.

\section{Author's Contributions}

All authors made substantial contributions to conception and design, acquisition of data, or analysis and interpretation of data; took part in drafting the article or revising it critically for important intellectual content; agreed to submit to the current journal; gave final approval of the version to be published; and agree to be accountable for all aspects of the work.

\section{Disclosure}

Dr. Pérez de Llano reports grants, personal fees and nonfinancial support from AstraZeneca, personal fees and nonfinancial support from GSK, grants and personal fees from TEVA, personal fees and non-financial support from Novartis, personal fees and non-financial support from Chiesi, personal fees and non-financial support from Boehringer, personal fees from Sanofi, personal fees from Menarini, personal fees and non-financial support from Mundipharma, grants and personal fees from Esteve, personal fees from ROVI, personal fees from BIAL, personal fees from MSD, personal fees from TECHDOW PHARMA, non-financial support from FAES, outside the submitted work. The authors report no other conflicts of interest in this work.

\section{References}

1. Global Initiative for Asthma (GINA). Available from: https:// ginasthma.org/gina-reports/. Accessed August 30, 2020.

2. World Health Organization. Questions and answers: asthma. Available from: https://www.who.int/news-room/q-a-detail/asthma. Accessed August 30, 2020.

3. Ebmeier S, Thayabaran D, Braithwaite I, Bénamara C, Weatherall M, Beasley R. Trends in international asthma mortality: analysis of data from the WHO mortality database from 46 countries (1993-2012). Lancet. 2017;390(10098):935-945. doi:10.1016/S0140-6736(17)31448-4
4. Levy ML. The national review of asthma deaths: what did we learn and what needs to change? Breathe (Sheff). 2015;11(1):14-24. doi: $10.1183 / 20734735.008914$

5. Price D, Fletcher M, van der Molen T. Asthma control and management in 8000 European patients: the REcognise Asthma and LInk to Symptoms and Experience (REALISE) survey. NPJ Prim Care Respir Med. 2014;24(1):14009. doi:10.1038/npjpcrm.2014.9

6. Demoly P, Annunziata K, Gubba E, Adamek L. Repeated cross-sectional survey of patient-reported asthma control in Europe in the past 5 years. Eur Respir Rev. 2012;21(123):66-74. doi:10.1183/09059180.00008111

7. Moore WC, Meyers DA, Wenzel SE, et al. Identification of asthma phenotypes using cluster analysis in the severe asthma research program. Am J Respir Crit Care Med. 2010;181(4):315-323. doi:10.1164/rccm.200906-0896OC

8. Haldar P, Pavord ID, Shaw DE, et al. Cluster analysis and clinical asthma phenotypes. Am J Respir Crit Care Med. 2008;178 (3):218-224. doi:10.1164/rccm.200711-1754OC

9. Loza MJ, Djukanovic R, Chung KF, et al. Validated and longitudinally stable asthma phenotypes based on cluster analysis of the ADEPT study. Respir Res. 2016;17(1):165. doi:10.1186/s12931016-0482-9

10. Lefaudeux D, De Meulder B, Loza MJ, et al. U-BIOPRED clinical adult asthma clusters linked to a subset of sputum omics. J Allergy Clin Immunol. 2017;139(6):1797-1807. doi:10.1016/j.jaci.201 6.08.048

11. Boudier A, Curjuric I, Basagana X, et al. Ten-year follow-up of cluster-based asthma phenotypes in adults. A pooled analysis of three cohorts. Am J Respir Crit Care Med. 2013;188(5):550-560. doi:10.1164/rccm.201301-0156OC

12. Boudier A, Chanoine S, Accordini S, et al. Data-driven adult asthma phenotypes based on clinical characteristics are associated with asthma outcomes twenty years later. Allergy. 2019;74(5):953-963. doi:10.1111/all.13697

13. Lötvall J, Akdis CA, Bacharier LB, et al. Asthma endotypes: a new approach to classification of disease entities within the asthma syndrome. $J$ Allergy Clin Immunol. 2011;127(2):355-360. doi:10.1016/j.jaci.2010.11.037

14. Woodruff PG, Modrek B, Choy DF, et al. T-helper type 2-driven inflammation defines major subphenotypes of asthma. Am J Respir Crit Care Med. 2009;180(5):388-395. doi:10.1164/rccm.2009030392OC

15. Green RH, Brightling CE, Woltmann G, Parker D, Wardlaw AJ, Pavord ID. Analysis of induced sputum in adults with asthma: identification of subgroup with isolated sputum neutrophilia and poor response to inhaled corticosteroids. Thorax. 2002;57(10):875-879. doi:10.1136/thorax.57.10.875

16. Pavlidis S, Takahashi K, Ng Kee Kwong F, et al. "T2-high" in severe asthma related to blood eosinophil, exhaled nitric oxide and serum periostin. Eur Respir J. 2019;53(1):1800938. doi:10.1183/ 13993003.00938-2018

17. Agusti A, Bel E, Thomas M, et al. Treatable traits: toward precision medicine of chronic airway diseases. Eur Respir J. 2016;47 (2):410-419. doi:10.1183/13993003.01359-2015

18. Pavord ID, Beasley R, Agusti A, et al. After asthma: redefining airways diseases. Lancet. 2018;391(10118):350-400. doi:10.1016/ S0140-6736(17)30879-6

19. McDonald VM, Fingleton J, Agusti A, et al. Treatable traits: a new paradigm for 21st century management of chronic airway diseases: treatable traits down under international workshop report. Eur Respir J. 2019;53(5):1802058. doi:10.1183/13993003.02058-2018

20. McDonald VM, Clark VL, Cordova-Rivera L, Wark PAB, Baines KJ, Gibson PG. Targeting treatable traits in severe asthma: a randomised controlled trial. Eur Respir J. 2020;55(3):1901509. doi:10.1183/ 13993003.01509-2019 
21. Pérez de Llano L, Miravitlles M, Golpe R, et al. A proposed approach to Chronic Airway Disease (CAD) using therapeutic goals and treatable traits: a look to the future. Int J Chron Obstruct Pulmon Dis. 2020;15:2091-2100. doi:10.2147/COPD.S263430

22. Suissa S, Ernst P, Benayoun S, Baltzan M, Cai B. Low-dose inhaled corticosteroids and the prevention of death from asthma. $N$ Engl J Med. 2000;343(5):332-336. doi:10.1056/NEJM200008033430504

23. Gupta RP, Mukherjee M, Sheikh A, Strachan DP. Persistent variations in national asthma mortality, hospital admissions and prevalence by socioeconomic status and region in England. Thorax. 2018;73(8):706-712. doi:10.1136/thoraxjnl-2017-210714

24. Mroczek B, Kurpas D, Urban M, Sitko Z, Grodzki T. The influence of asthma exacerbations on health-related quality of life. $A d v \operatorname{Exp}$ Med Biol. 2015;873:65-77.

25. McCoy L, Redelings M, Sorvillo F, Simon P. A multiple cause-ofdeath analysis of asthma mortality in the United States, 1990-2001. J Asthma. 2005;42(9):757-763. doi:10.1080/02770900500308189

26. O'Byrne PM, Pedersen S, Lamm CJ, Tan WC, Busse WW; START Investigators Group. Severe exacerbations and decline in lung function in asthma. Am J Respir Crit Care Med. 2009;179(1):19-24. doi:10.1164/rccm.200807-1126OC

27. Bloechliger M, Reinau D, Spoendlin J, et al. Adverse events profile of oral corticosteroids among asthma patients in the UK: cohort study with a nested case-control analysis. Respir Res. 2018;19(1):75. doi:10.1186/s12931-018-0742-y

28. Ko FW, Hui DS, Leung TF, et al. Evaluation of the asthma control test: a reliable determinant of disease stability and a predictor of future exacerbations. Respirology. 2012;17(2):370-378. doi:10.1111/ j.1440-1843.2011.02105.x

29. Engelkes M, Janssens HM, de Jongste JC, Sturkenboom MC, Verhamme KM. Medication adherence and the risk of severe asthma exacerbations: a systematic review. Eur Respir J. 2015;45 (2):396-407. doi:10.1183/09031936.00075614

30. Tran N, Coffman JM, Sumino K, Cabana MD. Patient reminder systems and asthma medication adherence: a systematic review. J Asthma. 2014;51(5):536-543. doi:10.3109/02770903.2014.888572

31. Normansell R, Kew KM, Stovold E. Interventions to improve adherence to inhaled steroids for asthma. Cochrane Database Syst Rev. 2017;4:CD012226. doi:10.1002/14651858.CD012226. pub2

32. Polosa R, Russo C, Caponnetto P, et al. Greater severity of new onset asthma in allergic subjects who smoke: a 10-year longitudinal study. Respir Res. 2011;12(1):16. doi:10.1186/1465-9921-12-16

33. Lazarus SC, Chinchilli VM, Rollings NJ, et al. Smoking affects response to inhaled corticosteroids or leukotriene receptor antagonists in asthma. Am J Respir Crit Care Med. 2007;175(8):783-790. doi:10.1164/rccm.200511-1746OC

34. Chaudhuri R, Livingston E, McMahaon AD, et al. Effects of smoking cessation on lung function and airway inflammation in smokers with asthma. Am J Respir Crit Care Med. 2006;174(2):127-133. doi:10.1164/rccm.200510-15890C

35. Pérez De Llano LA, González FC, Añón OC, Perea MP, Caruncho MV, Villar AB. Relationship between comorbidity and asthma control. Arch Bronconeumol. 2010;46(10):508-513. doi:10.1016/j.arbres.2010.05.008

36. Bachert C, Zhang L, Gevaert P. Current and future treatment options for adult chronic rhinosinusitis: focus on nasal polyposis. $J$ Allergy Clin Immunol. 2015;136(6):1431-1440. doi:10.1016/j.jaci.201 5.10 .010

37. Serrano-Pariente J, Plaza V, Soriano JB, et al.; CPASMA Trial Group. Asthma outcomes improve with continuous positive airway pressure for obstructive sleep apnea. Allergy. 2017;72(5):802-812. doi:10.1 111/all.13070.

38. Kitch BT, Paltiel AD, Kuntz KM, et al. A single measure of $\mathrm{FEV}_{1}$ is associated with risk of asthma attacks in long-term follow-up. Chest. 2004;126(6):1875-1882. doi:10.1378/chest.126.6.1875
39. Schatz M, Sorkness CA, Li JT, et al. Asthma control test: reliability, validity, and responsiveness in patients not previously followed by asthma specialists. J Allergy Clin Immunol. 2006;117(3):549-556. doi:10.1016/j.jaci.2006.01.011

40. Ha K, Engel M, Dahl R, et al. Tiotropium in asthma poorly controlled with standard combination therapy. $N$ Engl J Med. 2012;367 (13):1198-1207. doi:10.1056/NEJMoa1208606

41. Casale TB, Bateman ED, Vandewalker M, et al. Tiotropium respimat add-on is efficacious in symptomatic asthma, independent of T2 phenotype. J Allergy Clin Immunol Pract. 2018;6(3):923-935. doi:10.1016/j.jaip.2017.08.037

42. Schleich FN, Chevremont A, Paulus V, et al. Importance of concomitant local and systemic eosinophilia in uncontrolled asthma. Eur Respir J. 2014;44(1):97-108. doi:10.1183/09031936.00201813

43. Cowan DC, Taylor DR, Peterson LE, et al. Biomarker-based asthma phenotypes of corticosteroid response. J Allergy Clin Immunol. 2015;135(4):877-883. doi:10.1016/j.jaci.2014.10.026

44. Petsky HL, Li A, Chang AB. Tailored interventions based on sputum eosinophils versus clinical symptoms for asthma in children and adults. Cochrane Database Syst Rev. 2017;8:CD005603. doi:10.1002/14651858.CD005603.pub3

45. Farne HA, Wilson A, Powell C, Bax L, Milan SJ. Anti-IL5 therapies for asthma. Cochrane Database Syst Rev. 2017;9:CD010834. doi:10.1002/14651858.CD010834.pub3

46. Gibson PG, Yang IA, Upham JW, et al. Effect of azithromycin on asthma exacerbations and quality of life in adults with persistent uncontrolled asthma (AMAZES): a randomized, double-blind, placebo-controlled trial. Lancet. 2017;390(10095):659-668. doi:10.1016/S0140-6736(17)31281-3

47. Abramson MJ, Puy RM, Weiner JM, Allergen immunotherapy for asthma. Cochrane Database Syst Rev. 2003;(4):CD001186. doi:10.1002/14651858.CD001186

48. Cipriani F, Calamelli E, Ricci G. Allergen avoidance in allergic asthma. Front Pediatr. 2017;5:103. doi:10.3389/fped.2017.00103

49. Petsky HL, Kew KM, Turner C, Chang AB. Exhaled nitric oxide levels to guide treatment for adults with asthma. Cochrane Database Syst Rev. 2016;9:CD011440. doi:10.1002/14651858.CD011440.pub2

50. Sont JK, Willems LN, Bel EH, van Krieken JH, Vandenbroucke JP, Sterk PJ; The AMPUL Study Group. Clinical control and histopathologic outcome of asthma when using airway hyperresponsiveness as an additional guide to long-term treatment. Am J Respir Crit Care Med. 1999;159(4):1043-1051. doi:10.1164/ajrccm.159.4.9806052

51. Dusser D, Montani D, Chanez P, et al. Mild asthma: an expert review on epidemiology, clinical characteristics and treatment recommendations. Allergy. 2007;62(6):591-604. doi:10.1111/j.13989995.2007.01394.x

52. Stanford RH, Shah MB, D'Souza AO, Dhamane AD, Schatz M. Short-acting $\beta$-agonist use and its ability to predict future asthmarelated outcomes. Ann Allergy Asthma Immunol. 2012;109 (6):403-407. doi:10.1016/j.anai.2012.08.014

53. O’Byrne PM, FitzGerald JM, Bateman ED, et al. Inhaled combined budesonide-formoterol as needed in mild asthma. $N$ Engl $J$ Med. 2018;378(20):1865-1876. doi:10.1056/NEJMoa1715274

54. Bateman ED, Reddel HK, O'Byrne PM, et al. As-needed budesonide-formoterol versus maintenance budesonide in mild asthma. N Engl J Med. 2018;378(20):1877-1887. doi:10.1056/ NEJMoa1715275

55. Beasley R, Holliday M, Reddel HK, et al. Controlled trial of budesonide-formoterol as needed for mild asthma. $N$ Engl $J$ Med. 2019;380(21):2020-2030. doi:10.1056/NEJMoa1901963

56. Hardy J, Baggott C, Fingleton J, et al. Budesonide-formoterol reliever therapy versus maintenance budesonide plus terbutaline reliever therapy in adults with mild to moderate asthma (PRACTICAL): a 52-week, open-label, multicentre, superiority, randomised controlled trial. Lancet. 2019;394(10202):919-928. doi:10.1016/S01406736(19)31948-8 
57. Beasley R, Harper J, Bird G, Maijers I, Weatherall M, Pavord ID. Inhaled corticosteroid therapy in adult asthma. time for a new therapeutic dose terminology. Am J Respir Crit Care Med. 2019;199 (12):1471-1477. doi:10.1164/rccm.201810-1868CI

58. Holt S, Suder A, Weatherall M, Cheng S, Shirtcliffe P, Beasley R. Dose-response relation of inhaled fluticasone propionate in adolescents and adults with asthma: meta-analysis. BMJ. 2001;323 (7307):253-256. doi:10.1136/bmj.323.7307.253

59. Masoli M, Holt S, Weatherall M, Beasley R. Dose-response relationship of inhaled budesonide in adult asthma: a meta-analysis. Eur Respir J. 2004;23(4):552-558. doi:10.1183/09031936.04.00076604

60. O'Sullivan S, Cormican L, Murphy M, Poulter LW, Burke CM. Effects of varying doses of fluticasone propionate on the physiology and bronchial wall immunopathology in mild-to-moderate asthma. Chest. 2002;122(6):1966-1972. doi:10.1378/chest.122.6.1966

61. Daley-Yates P, Brealey N, Thomas S, et al. Therapeutic index of inhaled corticosteroids in asthma: a dose-response comparison on airway hyperresponsiveness and adrenal axis suppression. $\mathrm{Br} \mathrm{J}$ Clin Pharmacol. 2021;87(2):483-493. doi:10.1111/bcp.14406

62. Papi A, Canonica GW, Maestrelli P, et al. Rescue use of beclomethasone and albuterol in a single inhaler for mild asthma. $N$ Engl J Med. 2007;356(20):2040-2052. doi:10.1056/NEJMoa063861

63. McGrath KW, Icitovic N, Boushey HA, et al. A large subgroup of mild-to-moderate asthma is persistently noneosinophilic. Am J Respir Crit Care Med. 2012;185(6):612-619. doi:10.1164/rccm.201109$16400 \mathrm{C}$

64. Lazarus SC, Krishnan JA, King TS, et al. Mometasone or tiotropium in mild asthma with a low sputum eosinophil level. $N$ Engl J Med. 2019;380(21):2009-2019. doi:10.1056/NEJMoa1814917

65. Clark DJ, Lipworth BJ. Adrenal suppression with chronic dosing of fluticasone propionate compared with budesonide in adult asthmatic patients. Thorax. 1997;52(1):55-58. doi:10.1136/thx.52.1.55

66. Wechsler ME, Laviolette M, Rubin AS, et al. Bronchial thermoplasty: long-term safety and effectiveness in patients with severe persistent asthma. $J$ Allergy Clin Immunol. 2013;132(6):1295-1302. doi:10.1016/j.jaci.2013.08.009
67. Pérez de Llano LA, Quirce GS, Plaza MV. Treatment of moderate-severe asthma: an alternative strategy to the guidelines recommendations. Arch Bronconeumol. 2020.

68. Lee LA, Bailes Z, Barnes N, et al. Efficacy and safety of once-daily single-inhaler triple therapy (FF/UMEC/VI) versus FF/VI in patients with inadequately controlled asthma (CAPTAIN): a double-blind, randomised, Phase 3A trial. Lancet Respir Med. 2021;9(1):69-84. doi:10.1016/S2213-2600(20)30389-1

69. Kerstjens HAM, Maspero J, Chapman KR, et al. Once-daily, single-inhaler mometasone-indacaterol-glycopyrronium versus mometasone-indacaterol or twice-daily fluticasone-salmeterol in patients with inadequately controlled asthma (IRIDIUM): a randomised, double-blind, controlled phase 3 study. Lancet Respir Med. 2020;8(10):1000-1012. doi:10.1016/S2213-2600(20)30190-9

70. Virchow JC, Kuna P, Paggiaro P, et al. Single inhaler extrafine triple therapy in uncontrolled asthma (TRIMARAN and TRIGGER): two double-blind, parallel-group, randomised, controlled phase 3 trials. Lancet. 2019;394(10210):1737-1749. doi:10.1016/S0140-6736(19) 32215-9

71. Agache I, Akdis CA, Akdis M, et al. EAACI biologicals guidelines-Recommendations for severe asthma. Allergy. 2021;76 (1):14-44. doi:10.1111/all.14425

72. Diamant Z, Vijverberg S, Alving K, et al. Toward clinically applicable biomarkers for asthma: an EAACI position paper. Allergy. 2019;74(10):1835-1851. doi:10.1111/all.13806

73. Wagener AH, de Nijs SB, Lutter R, et al. External validation of blood eosinophils, $\mathrm{FE}(\mathrm{NO})$ and serum periostin as surrogates for sputum eosinophils in asthma. Thorax. 2015;70(2):115-120. doi:10.1136/ thoraxjnl-2014-205634

74. Soma T, Iemura H, Naito E, et al. Implication of fraction of exhaled nitric oxide and blood eosinophil count in severe asthma. Allergol Int. 2018;67:S3-S11. doi:10.1016/j.alit.2018.04.003

75. Castro M, Corren J, Pavord ID, et al. Dupilumab efficacy and safety in moderate-to-severe uncontrolled asthma. $N$ Engl J Med. 2018;378 (26):2486-2496. doi:10.1056/NEJMoa1804092

\section{Publish your work in this journal}

The Journal of Asthma and Allergy is an international, peer-reviewed open-access journal publishing original research, reports, editorials and commentaries on the following topics: Asthma; Pulmonary physiology; Asthma related clinical health; Clinical immunology and the immunological basis of disease; Pharmacological interventions and new therapies. The manuscript management system is completely online and includes a very quick and fair peer-review system, which is all easy to use. Visit http://www.dovepress.com/testimonials.php to read real quotes from published authors. 